\title{
EDITORIAL
}

\section{Mind Your Ecosystem!}

$\mathrm{M}$ ankind has long been wedded to monocultures. Throughout recorded history, men and women have cleared plots in forests and sown them with whatever crop seemed likely to prove most usefully productive for themselves or their associates. The choice in each case must have been from among the known range allowed by local climatic and other conditions, and was almost invariably of a monoculture. This was (and often still is) in Europe of wheat or some other cereal or a pulse; in North America, of maize; and in the Orient, of rice. It seems to have been chiefly in the most recent centuries, and for particular purposes or at least reasons, that dicultures and even polycultures were used and became widespread in increasingly organized agriculture-as still nowadays in some primitive cultures for example in Africa. But in any case the sowing and clear-cropping of a single-entity harvest became ingrained in human cultures practically throughout the world.

Now what is the outcome? As human population-pressures build up there are ever-increasing demands on Earth's limited resources for crop-growing space, more and more 'flogging' of good soils with over-cultivation, and ever-expanding conversion of 'marginal' and even wholly unsuitable areas to attempted crop production - with resultant, increasingly devastating erosion and expanding desertification. These and many other results of Mankind's impact on the more habitable terrestrial portions of The Biosphere are well known to us all, or at least to readers of our Journal and sponsored books, and matters are little better in the world's restricted seas. Even the vast oceans are beginning to suffer concomitantly, as are such less-hospitable parts as the Sahel, the Arctic, and the Antarctic.

And the remedy? Apart from the urgent imperative of freeing the world from the threat of nuclear devastation, and the gradual one of curbing human population-pressures, we have come to believe that a widespread seeing and acting in an ecosystem context could be of the greatest material help both short-term and long-term. The short-term viewing on the large scale could, for example, ensure at least some saving of Nature's remaining virgin forests and the vast wealth of plants and animals - not to mention gene-poolsthat would disappear with them, by practising controlled selective use rather than devastating clearance. The long-term viewing on the small scale should be towards having people everywhere, while acting locally, thinking always biospherally - about what effects their actions may have on soils, fresh waters, salt seas, the ambient atmosphere, and even on the stratospheric ozone shield without which life could scarcely have evolved on Earth, much less be equably maintained.

The long-term viewing overall is the ultimate objective-surely attainable, though scarcely with the world in its currently disrupted state - of having all humanity acting in an ecosystems context. This should range from care by each person of his or her immediate habitat in every possible way-starting with its cleanliness and general 'health' - through enlightened maintenance of each local ecosystem, whether natural or artificial, to care for it in the global context as an integral part of The Biosphere. And even as each of those myriad ecosystems comprising The Biosphere is an integral part of it, so is each unit of Earth's living biota -including Mankind. Thus each man, woman, and human child, on Earth is an integral part of his or her immediate ecosystem and hence, ultimately, of The Biosphere; and as the human species has latterly come to occupy a situation of excessive pandominance in (and almost of) the world as a whole, it behoves every component of that species to act accordingly for the good of all.

That is our dream, and was behind our thinking when urging the establishment of the World Campaign for The Biosphere* and of its fostering World Council For The Biosphere $\dagger$ together with its allied activator the International Society For Environmental Education $\dagger \dagger$.

But to return in conclusion to the subject of ecosystems. We define an ecosystem as: 'The total components of an immediate environment or recognizable habitat, including both the inorganic and dead parts of the system and the various organisms that live together in it as a social unit, so far as its characteristic dominance or influence-sphere extends.' The ecosystem is thus characterized and dominated by a particular species or group of ecologically similar species, whereas the wider unit, usually comprising a multiplicity of ecosystems, is the ecobiome, which is characterized by the dominance of a particular life-form**_on land most widely by vascular plants, or, in towns, by human beings.

\footnotetext{
* See, for example, 'Our global environment and the World Campaign for The Biosphere', Environmental Conservation, 9(2), pp. 115-21, 2 figs, 1982.

$\dagger$ See, for example, 'Geneses and progress of the World Campaign and Council For The Biosphere', Ibid., 11(4), pp. 293-8, 2 figs, 1984.

$\dagger+$ See, for example, 'The origin, evolution, and status, of the International Society For Environmental Education (ISEE)', by Drs John H. Baldwin \& Arthur B. Sacks, Ibid., 11(4), pp. 313-7, 1984.

** Editorial Note: Our use of 'Biosphere', 'Ecosystem', and now 'Ecobiome', Ibid., 11(3), p. 198, 1984.
} 
Finally we should note the ubiquitous importance of holistic effects, namely the tendency of Nature to produce, from the ordered groupings of unit structures such as comprise ecosystems and ecobiomes, wholes that are different from - and usually far more complex than - the sum of the component parts. This brings us back to the ecologists' adage that 'everything is connected with everything else'- which we should remember, for example, when clear-harvesting a dominant forest tree or depopulating a predatory species of fish!

Nicholas Polunin

\section{EDITORIAL NOTICE}

\section{Free Offprint and Other Savings Towards Hoped for Awards for Outstanding Contributions}

After consultation and due deliberation we have decided that, starting with Volume 13 No. 1 of our Journal, Environmental Conservation, we will give out our customary 50 free offprints of signed editorial items, 'full' papers, Short Communications \& Reports, and items in the section of Notes, New \& Comments, only when they are asked for. Such asking is a right of the Authors involved and should continue to be done normally by them when they return their corrected proofs to the Editor.

The simplest procedure is to complete the green ordering form which is sent with proofs to all (first-named) Authors and which henceforth will be amended accordingly, though exceptionally such requests, in the manner of special orders, may be entertained in writing or by cable or telephone from Authors or others up to the time of final passage for printing. (Orders for any desired additional offprints or the more costly reprints with covers, should be made similarly. but accompanied wherever possible by payment to ensure action and simplify procedures-such payment being according to the scales given in the ordering form and including packaging and registered postage.)

\section{Copyright Enforcement}

Our items in Environmental Conservation being, with rare exceptions, copyrighted by the Foundation, we get very frequent requests for permission for reprinting or photocopying from all manner of sources: these are usually granted, though with requests for modest royalty fees (of US $\$ 100$ to $\$ 500$ or equivalent according to length and other circumstances) where items are to be for sale, or e.g. chapters in books that are to be sold. On the other, most regrettable, hand it is said that it is now a common practice in many unscrupulous circles to disregard copyright and photocopy publications practically ad lib. ("the machines are so good and the processes so inexpensive when used in bulk').

On realizing that this illegal copying may largely explain why-although we used to get frequent orders for 2,000 or more offprints and/or reprints with covers of a paper or short communication published in our Journal-we now scarcely ever approach such a figure from any single source, we telephoned the World Intellectual Property Organization (WIPO, alias OMPI), whence various voices informed us that, owing to the very different laws prevailing in different countries, there is not much they can do about 'such piracy' on a world basis except to plead for restraint on moral grounds. They are, however, most earnestly requesting their $112 \mathrm{Member}$ States to strengthen the enforcement of their national copyright laws, and cited the instance of one major country that has raised its maximum penalty for such flouting piracy to US $\$ 250,000$.

\section{Savings for Awards}

Whereas it is rare for the 50 free offprints of a 'full' paper in our Journal not to be claimed on the green ordering form as explained above, it is sufficiently common for items in the other categories to make the overall savings-and not merely of costs now that overseas postage of printed matter from Switzerland is being greatly increased, but also those of materials and services-quite substantial. This will accrue to the Foundation for Environmental Conservation, the Governing Board of which has approved those changes, as have our governmental supervisors in Geneva and Berne.

Another source of saving is through our new printers' use of electronic recordings and galley-proofs, which can be corrected early in the proceedings at minimal cost - though all our Authors can still help substantially by adhering closely to our set style of hyphenation, use of commas etc., and regularized headings of all items in the Conferences \& Meetings and Reviews \& Notices sections of our Journal, so saving in matters of tedious and costly correspondence etc. We also require all literature References to be given in full-not 'the lazy way' without details, which last for us must include publisher, place of publication, and pagespreads, in the case of books and other 'separate' publications, and in all cases indication of whether 'illustr.'.

\section{Prizes for Best Contributions}

From the savings indicated above, we hope to institute a yearly Foundation Prize of not less than 1,000 Swiss francs or US $\$ 500$ for the best paper or other contribution published either in the preceding year's volume of our Journal or as a chapter or section of a book in either of our sponsored series, with a consolation award of not less than half of the prize amount at least if donated as expected by an interested body. The Foundation Prize would accomplish one of our long-term objectives, and the consolation award would actually improve on it. The choices would be made by a confidential ad hoc Awards Committee (appointed by the Foundation for Environmental Conservation, owner and copyright-holder of the Journal), whose Chairman should report to the Editor in time for publication of a suitable announcenent in the Spring issue of the Journal.

Whereas enlightened suggestions would of course be welcomed, our present thinking is that the ad hoc Awards Committee might be asked to bear in mind the following as guidelines in making their selections: (a) most significant advance, (b) greatest potential influence for environmental good, and (c) quality of presentation. 